\title{
Role of stanniocalcin-1 in breast cancer (Review)
}

\author{
FENGXIA CHEN $^{1,2}$, ZHICAI ZHANG ${ }^{3}$ and FEIFEI PU ${ }^{4}$ \\ ${ }^{1}$ Department of Medical Oncology, General Hospital of The Yangtze River Shipping, Wuhan, Hubei 430010; \\ ${ }^{2}$ Department of Radiation and Medical Oncology, Zhongnan Hospital of Wuhan University, Wuhan, Hubei 430071; \\ ${ }^{3}$ Department of Orthopedics, Union Hospital, Tongji Medical College; ${ }^{4}$ Department of Orthopedics, \\ Wuhan No. 1 Hospital, Wuhan Integrated Traditional Chinese Medicine and Western Medicine Hospital, \\ Tongji Medical College, Huazhong University of Science and Technology, Wuhan, Hubei 430022, P.R. China
}

Received January 1, 2019; Accepted July 16, 2019

DOI: $10.3892 / \mathrm{ol} .2019 .10777$

\begin{abstract}
Breast cancer is a highly heterogeneous disease consisting of five disease subtypes with distinct histological characteristics, clinical behaviors and prognostic features. Stanniocalcin-1 (STC1) is a secreted glycoprotein hormone that has been demonstrated to regulate calcium and phosphate homeostasis. Mammalian STC1 is expressed in various tissues and is implicated in multiple physiological and pathophysiological processes. In addition, growing evidence has suggested that STC1 serves an oncogenic role in a number of different types of tumor. However, the role of STC1 in breast cancer is complex, considering that some studies have shown that it exerts an oncogenic role, whereas other studies have demonstrated the opposite. The aim of the present review article is to evaluate the currently available data on mammalian STC1 and discuss its potential roles in each subtype of breast cancer.
\end{abstract}

\section{Contents}

1. Introduction

2. STC1 is implicated in TNBC invasion and metastasis

3. STC1 expression as a prognostic factor in breast cancer

4. Effect of STC1 expression on the proliferation of breast cancer cells

5. Correlation between STC1 expression and breast cancer chemotherapy resistance

6. Conclusions

Correspondence to: Dr Feifei Pu, Department of Orthopedics, Wuhan No. 1 Hospital, Wuhan Integrated Traditional Chinese Medicine and Western Medicine Hospital, Tongji Medical College, Huazhong University of Science and Technology, 215 Zhongshan Road, Wuhan, Hubei 430022, P.R. China

E-mail: pufeifeiemail@163.com

Key words: stanniocalcin-1, stanniocalcin-2, glycoprotein hormone, breast cancer, triple-negative breast cancer

\section{Introduction}

Breast cancer is the most commonly diagnosed cancer and the leading cause of cancer-associated death among females worldwide. There were an estimated 1.7 million cases of breast cancer and 521,900 deaths in 2012, accounting for $25 \%$ of all cancer diagnoses and $15 \%$ of all cancer-associated deaths in women (1). Breast cancer is a highly heterogeneous disease that is classified into five different molecular subtypes based on the presence or absence of estrogen receptors (ERs), progesterone receptors (PRs) and human epidermal growth factor receptor 2 (HER2/neu) (2). Among the five subtypes, the most commonly observed subtypes in clinical practice are Luminal A, Luminal B, HER2 ${ }^{+}$and triple-negative breast cancer (TNBC). Luminal A is associated with ER and PR expression, and represents $50-60 \%$ of all breast cancer cases, luminal B is $\mathrm{ER}^{+}, \mathrm{PR}^{+/-}$and HER2 ${ }^{+/-}$, and represents $10-20 \%$ of all breast cancer cases, and HER2 ${ }^{+}$is characterized by HER2/neu upregulation and represents $\sim 20 \%$ of all breast cancer cases. TNBC is negative for ER, PR and Her $2 /$ neu, and constitutes $\sim 20 \%$ of all breast cancer cases $(3,4)$. As the five subtypes exhibit distinct gene expression profiles, mutational spectrum and copy number variations, each subtype has unique histological characteristics, biological and clinical behaviors, and prognostic features (3). Metastasis is responsible for $90 \%$ of all cancer-associated deaths and is the primary clinical challenge of treating solid tumors (5). Therefore, investigating the mechanisms underlying metastasis is important for improving breast cancer therapy and prognosis.

Stanniocalcin-1 (STC1) is a 56-kDa disulfide-bound glycoprotein hormone that was first identified in bony fish and is involved in plasma calcium and phosphate homeostasis (6). Human STC1 was identified as a differentially expressed mRNA associated with cellular immortalization, a key feature of the cancer cell phenotype (7). The human STC1 gene maps to chromosome 8p21-p11.2, which shares $73 \%$ homology with the fish Stc gene and encodes a 247 -amino acid protein. STC1 exists as a homodimer, and through the presence of a signal peptide, it is secreted into the extracellular matrix in an autocrine or paracrine manner (7-10). Mammalian STC1 is expressed in various tissues, including the endocrine glands and hormone-responsive organs (11). Among all tissues, the 
ovaries contain the highest STC1 expression levels, with elevated expression observed during pregnancy and lactation (11). STC1 has been implicated in multiple physiological and pathophysiological processes, including, but not limited to, pregnancy, angiogenesis, organogenesis, cell proliferation, apoptosis, suppression of oxidative stress, retinal degeneration, cerebral ischemia and inflammation (10,12-14). In addition, accumulating evidence has suggested that the aberrant expression of STC1 serves a role in various types of cancer. STC1 triggers tumor angiogenesis by upregulating the expression of vascular endothelial growth factor in gastric cancer cells (15). Abnormal STC1 expression is also typically associated with tumorigenesis and poor clinical outcomes in ovarian, colorectal and lung cancer (16-18). Therefore, STC1 confers a malignant phenotype to various types of cancer. However, the clinical significance of STC1 expression in breast cancer has not been well established. At present, studies have primarily focused on the association between STC1 and breast cancer invasion and metastasis (19-22). However, other studies have suggested that STC1 is involved in tumor growth and chemotherapy resistance in breast cancer $(20,22,23)$. Emerging evidence has shown that STC1 is a novel biomarker that may be useful for predicting the recurrence and prognosis of breast cancer $(19,21,22,24-27)$. However, whereas some studies have demonstrated an oncogenic role for STC1 in breast cancer $(20,22,26,28)$, other studies have reported contradictory results $(27,29,30)$. Accordingly, it is necessary to elucidate the roles of STC1 in breast cancer.

STC2 is a paralog of STC1 that was identified by searching expressed sequence tag databases for sequences related to STC1 (31-33). The human Stc2 gene localizes to chromosome $5 q 33$ or $5 q 35(34,35)$, which encodes a protein containing 302 amino acids and shares $34 \%$ identity with both STC1 and eel STC (12). Similar to STC1, human STC2 is abundantly expressed in tissues, including the kidney, heart, pancreas and spleen (31-33). STC2 was first associated with breast cancer in a study designed to identify estrogen-regulated genes in breast cancer cell lines (36). Previous studies suggested that STC2 expression is inducible by estrogen and repressed by anti-estrogens $(36,37)$. In addition, STC2 was demonstrated to be induced by retinoic acid and progesterone in a number of breast cancer cell lines. In addition, STC2 acts in a paracrine or autocrine manner in hormone receptor-negative cell lines $(36,38)$. Iwao et al (39) first reported the clinical significance of STC2 expression in breast cancer. A total of 21 genes with prognostic value in breast cancer were identified, and low expression of these genes, including STC2, was associated with a poor prognosis (39). Yamamura et al (40) demonstrated that high STC2 expression was significantly associated with a favorable prognosis in patients with $\mathrm{ER}^{-}$and $\mathrm{PR}^{+}$breast cancer. Results of a tissue microarray screen showed that STC2 expression was associated with longer disease-free survival times (41). In 2008, Raulic et al (38) showed that constitutive STC2 expression impaired cell growth, viability and migration, suggesting that STC2 inhibits cell proliferation and motility. In a recent study, Coulson-Gilmer et al (42) reported that STC2 expression was associated with favorable outcomes in male breast cancer, where it served as an independent prognostic factor for disease-free survival. However, the mechanisms underlying the favorable clinical outcomes associated with STC2 remain unknown. Several studies have indicated the involvement of STC2 in the pregnancy-associated plasma protein-A (PAPP-A)-insulin like growth factor (IGF)-binding protein 4-IGF axis, as STC2 was demonstrated to potently inhibit PAPP-A activity by forming a covalent complex with PAPP-A (43-47). Additional studies are required to confirm these findings. Taken together, the aforementioned studies suggest that STC2 expression is associated with a more differentiated phenotype and improved prognosis in patients with breast cancer.

The aim of the present review is to elucidate the role of STC1 in breast cancer and the potential underlying mechanisms.

\section{STC1 is implicated in TNBC invasion and metastasis}

TNBC is a highly aggressive disease that is often associated with a poor prognosis and is more frequently diagnosed in younger women $(<50$ years old) (48-52). Given the lack of specific therapeutic targets, TNBC is insensitive to anti-hormonal and HER2-targeted therapies. At present, chemotherapy remains the primary treatment option for patients with TNBC (53). Although patients with TNBC are sensitive to chemotherapy, they often experience aggressive biological and clinical characteristics associated with an advanced histological grade, including rapid proliferation, shorter time to recurrence and higher risk of distant recurrence (51). Therefore, a number of studies have attempted to discover promising therapeutic targets for treating TNBC.

Recent studies have suggested that STC1 serves an oncogenic role in TNBC and is associated with invasion and metastasis. Murai et al (20) demonstrated that STC1 overexpression enhanced cell invasion in the human TNBC MDA-MB-231 cell line in vitro and promoted the pulmonary metastasis of the cells in vivo. Consistent with these findings, another study showed that STC1-knockdown reduced cell invasiveness and metastasis in murine and MDA-MB-231 cell lines (22). Furthermore, similar outcomes were observed in two other studies conducted by Han et al (19) and Jeon et al (21), in which elevated levels of STC1 were found to significantly increase the invasiveness and metastasis of TNBC cells.

The detailed mechanism by which STC1 stimulates TNBC cell invasion and metastasis remains to be fully elucidated. However, certain studies have shed light on this issue. Huang et al (54) showed that macrophage-capping protein, a metastasis-associated gene, inhibited the activity of arginine methyltransferase 5, a metastasis-suppressing gene that binds to the same region ( -451 to $-75 \mathrm{bp}$ ) in the STC1 promoter, which in turn promoted STC1 transcription and enhanced breast cancer metastasis. Another study reported contradictory results, suggesting that STC1 expression was upregulated via the phosphoinositide 3-kinase/protein kinase B (PI-3k/Akt) or nuclear factor- $\kappa \mathrm{B}(\mathrm{NF}-\kappa \mathrm{B})$-dependent signaling pathway in TNBC cells. Furthermore, the results indicated crosstalk between the Akt and NF- $\mathrm{NB}$ signaling pathways in the regulation of STC1 expression, as active Akt overexpression increased the phosphorylation levels of NF- $\kappa \mathrm{B}$ (21). Taken together, the results demonstrated that STC1 promotes the metastasis of TNBC cells by upregulating STC1 expression via the PI-3K/Akt/NF- $\kappa \mathrm{B}$-dependent signaling pathways (21). 


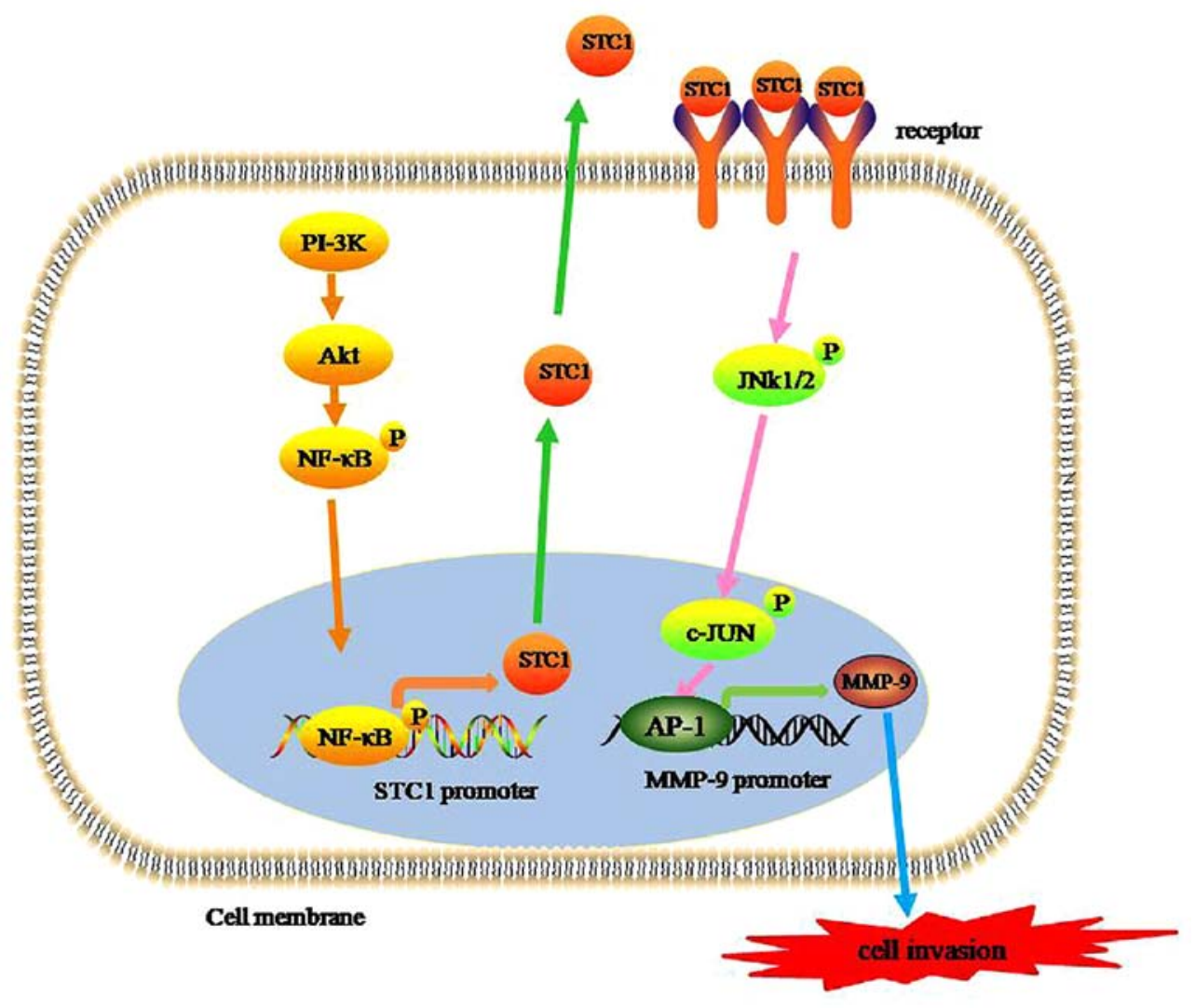

Figure 1. STC1 expression and cell invasion. STC1 expression is increased via a PI-3K/Akt/NF-kB-dependent signaling pathway. STC-1 protein is subsequently secreted into the extracellular matrix in an autocrine/paracrine manner. Secreted STC1 binds to its receptors on the surface of the cell membrane to form a complex which initiates the JNK/c-Jun signaling pathway. Activated c-Jun dimerizes with the Fos family of proteins to form AP-1, which activates MMP-9 transcriptional activity. Finally, increased MMP-9 expression results in increased cell invasion of triple-negative breast cancer cells as a result of extracellular matrix degradation. STC1, stanniocalcin-1; PI-3K, phosphoinositide 3-kinase; Akt, protein kinase B; NF- $\mathrm{B}$, nuclear factor-кB.

Han et al (19) demonstrated that high STC1 expression levels significantly increased the invasiveness of TNBC cells and that the process was mediated by phosphorylation of JNK/c-Jun, which in turn upregulated the expression of MMP-9.

Based on the pooled data, a schematic model of STC1 promoting the invasion and metastasis of TNBC can be hypothesized. First, STC1 expression levels are elevated via the $\mathrm{PI}-3 \mathrm{~K} / \mathrm{Akt} / \mathrm{NF}-\mathrm{\kappa B}$ signaling pathways. In turn, elevated STC1 levels promote MMP-9 transcriptional activity by activating the JNK/c-Jun signaling pathway and triggering the invasion and metastasis of TNBC cells (Fig. 1). Therefore, STC1 may be a promising therapeutic target for the treatment of TNBC.

\section{STC1 expression as a prognostic factor in breast cancer}

Several prognostic markers for breast cancer are used in contemporary clinical practice, including carcinoembryonic antigen, ER, PR and HER2 $(55,56)$. However, these individual markers cannot be reliably used to predict prognosis due to lack of specificity or sensitivity to breast cancer. Recently, multiple studies have indicated that the protein and mRNA expression levels of STC1 in tumors may be used as a valuable prognostic marker of breast cancer. McCudden et al (24) suggested that patients with breast cancer with strong positive staining for STC1 and its receptor had an increased incidence of lymph node involvement and ductal carcinoma in situ status. Similarly, Wascher et al (26) reported that STC1 mRNA levels in the bone marrow and blood of patients with breast cancer were significantly associated with the primary tumor size, number of positive lymph nodes and overall American Joint Committee on Cancer stage (57). In addition, the study highlighted the potential use of STC1 as a highly sensitive potential molecular marker for occult breast cancer cells in the bone marrow and blood of patients with breast cancer (26). STC1 may be used to identify subclinical metastatic breast cancer disease before it becomes clinically and radiographically visible (26). A retrospective study of 1,457 clinical samples found a significant association between high STC1 expression and a poor clinical outcome (22). However,Zandberga et al (25) showed that there was no significant association between STC1 levels and relapse-free survival (RFS), overall survival (OS) or distant metastasis-free survival (DMFS) when all patients with breast cancer were analyzed together without considering the intrinsic molecular subtypes separately. Breast cancer is a highly heterogeneous disease, and different breast cancer subtypes have different prognoses. Furthermore, some studies have indicated the potential predictive value of STC1 in different subtypes of breast cancer (Table I).

STC1 expression as a prognostic factor in TNBC. Multiple studies have shown that STC1 expression is upregulated in TNBC compared with that in other breast cancer subtypes and that it is associated with poor survival in patients with TNBC $(19,21,25)$. Zandberga et al (25) performed independent 


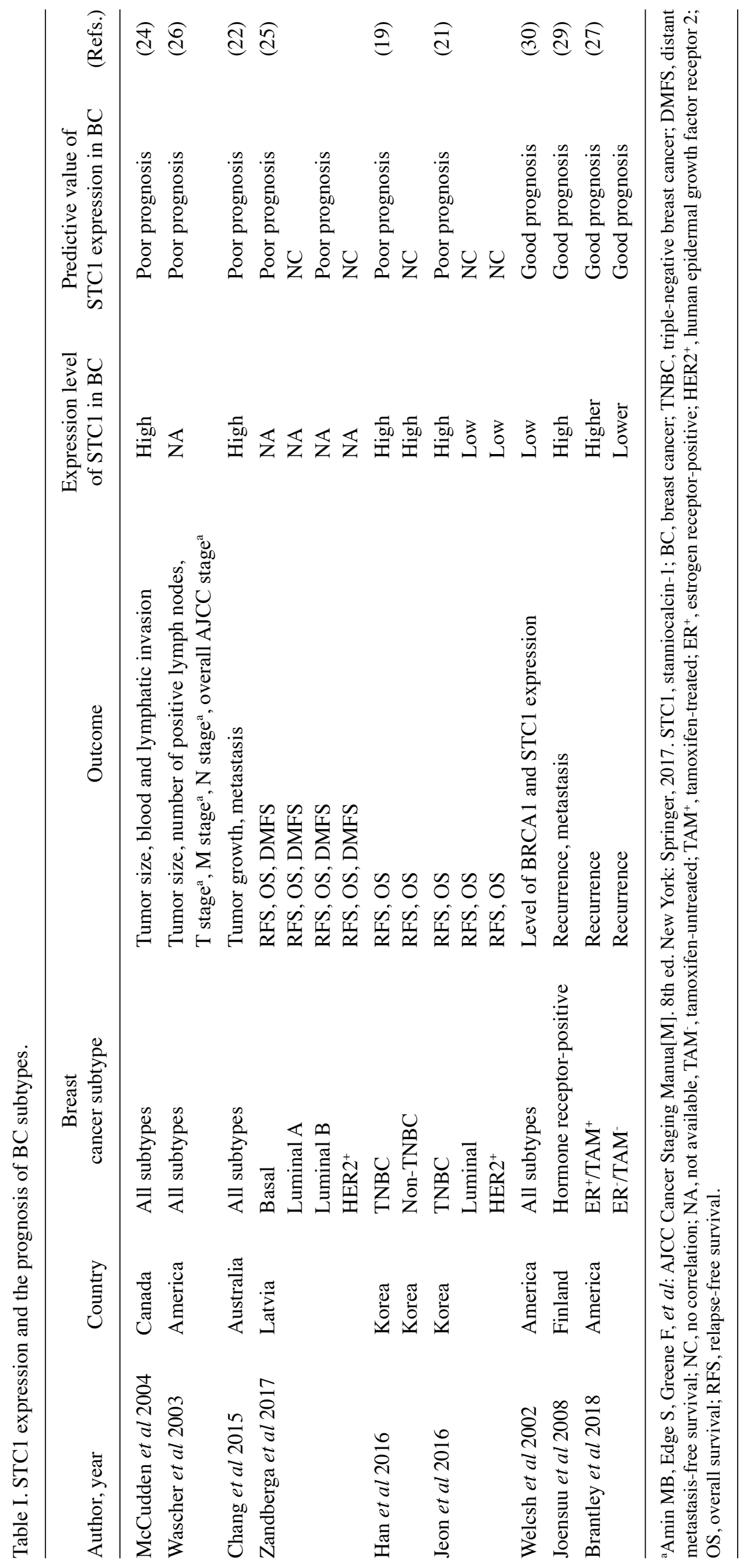


analysis of the intrinsic molecular subtypes and reported that upregulated expression of STC1 was significantly associated with shorter OS and RFS times in patients with the basal-type breast cancer (defined as ER//HER2-), but not with the luminal A and HER2 ${ }^{+}$subtypes. In the luminal B subtype, high STC1 expression was associated with a shorter DMFS time, but not with RFS and OS times. Furthermore, the association between high STC1 expression and shorter OS and RFS times was more evident when a subgroup of tumor protein p53 (TP53)-mutated basal-type breast cancer cases was analyzed. Taken together, the aforementioned findings suggested that in basal-type breast cancer, patients with upregulated expression of STC1 had a poor prognosis, and that patients with TP53 mutations in addition to high STC1 expression had a considerably less favorable prognosis (25). Han et al (19) and Jeon et al (21) showed that STC1 expression levels were significantly higher in TNBC cells than in non-TNBC cells. Patients of TNBC with high STC1 levels had shorter RFS and OS times. The conclusion of the two studies was that elevated STC1 expression was associated with a poor prognosis in patients with TNBC $(19,21)$.

Therefore, based on the results of the aforementioned studies, STC1 expression appears to be significantly higher in TNBC cells compared with that in non-TNBC cells. Furthermore, elevated STC1 expression is associated with a poor prognosis in patients with TNBC and promotes the invasiveness and metastasis of TNBC cells.

STC1 expression as a prognostic factor in hormone receptor-positive breast cancer. STC1 expression was found to be correlated with ER status, and STC1 receptors and ER are typically co-expressed in breast cancer (24). Furthermore, STC1 was expressed in only a subset of $\mathrm{ER}^{+}$breast cancer, which is a marker for favorable prognosis in breast cancer $(12,24,37)$. Bouras et al (37) reported that expression levels of STC1 and STC2 were more clinically useful than ER status. Furthermore, the tumor suppressor genes BRCA1 DNA repair-associated (BRCA1) and P53 were reported to induce STC1 expression (30). STC1 was found to be expressed in normal breast ductal epithelium, and loss of BRCA1 and STC1 expression was correlated in breast cancer (30). The two genes, BRCA1 and TP53, which are both tumor-suppressor genes and their proteins in cancer are usually associated with favorable prognosis (58-60).

In a study consisting of 72 primary breast cancer tissues and the corresponding metastatic tissues, STC1 expression levels were significantly higher in the metastases 5 and 10 years after surgery compared with those in the primary tumors with early metastases (29). Elevated STC1 expression contributed to tumor dormancy and was indicative of a risk for late recurrence (29). Similarly, another large study followed 3,634 Danish patients with breast cancer, including 1,826 $\mathrm{ER}^{+}$tamoxifen-treated $\left(\mathrm{TAM}^{+}\right)$patients and 1,808 $\mathrm{ER}^{-}$ tamoxifen-untreated patients $\left(\mathrm{TAM}^{-}\right)$who survived for at least 1 year without recurrence (27). The results showed that STC1 expression was higher, on average, among $\mathrm{ER}^{+} / \mathrm{TAM}^{+}$patients compared with that among $\mathrm{ER}^{-} / \mathrm{TAM}^{-}$patients. In addition, the study found an association between STC1 expression and recurrence in the primary tumors of women who experienced recurrence 6-10 years following primary diagnosis, but not in the tumors of women who experienced earlier recurrence (27).
However, another study showed that there was no association between STC1 expression levels and the survival of patients with luminal-type breast cancer (21). In general, it was suggested that high STC1 levels are associated with a favorable prognosis in hormone receptor-positive breast cancer based on the pooled studies.

Association between STC1 expression and prognosis of $H E R 2^{+}$breast cancer. There are only two studies that have demonstrated the correlation between STC1 expression and the prognosis of HER2 ${ }^{+}$breast cancer. The conclusions of the two studies were consistent with each other and suggested that there was no correlation between STC1 expression and the prognosis of patients with HER $2^{+}$breast cancer $(21,24,25)$. Considering the small number of studies on the HER2 ${ }^{+}$ subtype, further studies are required to validate these findings.

\section{Effect of STC1 expression on the proliferation of breast cancer cells}

Certain studies have reported that STC1 alters cell proliferation. However, the effect of STC1 expression on cell proliferation was found to vary among different types of cancer. STC1 was demonstrated to inhibit the proliferation of cervical cancer cells (61), but promoted tumor proliferation and cell colony formation in ovarian cancer. The potential mechanism underlying this observation may involve increasing the activity of cell cycle-regulated proteins and anti-apoptotic proteins, as well as inhibiting the activity of caspase-3/caspase-9 (17). Similarly, the conclusions of studies reporting the effects of STC1 on breast cancer proliferation were inconsistent. Welcsh et al (30), and Daniel and Lange (62) reported that STC1 contributes to breast cancer cell proliferation. Interestingly, in an independent experiment, it was observed that downregulation of STC1 expression slowed the rate of tumor growth in both murine and human breast cancer cells in vivo, but had no effects on proliferation in both models in vitro (22). Therefore, additional studies are required to further verify the effects of STC1 on breast cancer cell proliferation based on the intrinsic molecular subtype.

\section{Correlation between STC1 expression and breast cancer chemotherapy resistance}

Previous studies have shown that the aberrant expression of STC1 is involved in the chemotherapy resistance of various tumors. Liu et al (63) focused on investigating the microenvironment of lung cancer cells and identified a correlation between STC1 expression and chemotherapy resistance in lung cancer cells. Shirakawa et al (64) reported a similar conclusion in esophageal squamous cell carcinoma. Only one retrospective study from China indicated that STC1 expression in breast cancer tissue was associated with chemotherapy resistance in patients with breast cancer (23). Furthermore, the molecular mechanism mediating chemotherapy resistance remains unknown. Multiple studies have reported that STC1 expression is induced by hypoxia (16,65-69). Hypoxia-inducible factor- $1 \alpha$, which is involved in the chemotherapy resistance of tumor cells (70-72), can bind to the STC1 promoter and regulate its transcription (16,65-69). 
Based on these studies, we hypothesize that this is the mechanism underlying STC1-mediated chemotherapy resistance. However, further studies are required to examine and confirm the exact molecular mechanism underlying tumor chemotherapy resistance.

\section{Conclusions}

The roles of STC1 are complicated and varied in breast cancer. Furthermore, STC1 exhibits varying functions and prognostic value dependent on the breast cancer subtype. In TNBC, STC1 serves an oncogenic role and promotes invasiveness and metastasis. Furthermore, patients with TNBC with elevated levels of STC1 expression had poor prognosis. Accordingly, STC1 may serve as a promising therapeutic target for the treatment of TNBC. However, in hormone receptor-positive breast cancer, high STC1 expression levels were correlated with a favorable prognosis, but in HER2 ${ }^{+}$breast cancer, there was no correlation between STC1 expression and the prognosis. Similarly, the effects of STC1 expression on breast cancer cell proliferation are controversial. In this regard, tumor source, distinct gene expression and variability are likely to be at least partially responsible for the contrasting results. In addition, a few studies have suggested that STC1 expression is correlated with the chemotherapy resistance of breast cancer; however, the exact mechanism remains unknown. Some studies have also reported that STC1 may be used to identify subclinical metastatic breast cancer disease before it is clinically and radiographically visible. Therefore, STC1 may be a promising novel molecular marker and therapeutic target for the clinical diagnosis, treatment and prognosis evaluation of patients with breast cancer.

The present review contributes to the understanding of the role of STC1 in breast cancer and hypothesizes a mechanism by which STC1 may contribute to resistance to chemotherapy. The different roles of STC1 in the development of breast cancer were classified and discussed. The prognostic value of STC1 in breast cancer based on subtype was highlighted and is summarized in Table I. A conclusion was drawn based on combined results of the studies referenced, suggesting a potential schematic model by which STC1 promotes the invasion and metastasis of TNBC.

However, there are certain limitations in the present review. Only a limited number of studies have investigated the role of STC1 in breast cancer, therefore, the conclusions drawn in the present review are based on a small number of studies. Additionally, some of the studies referenced did not analyze the role of STC1 based on breast cancer subtype, which may have masked the role of STC1 in these studies as it seems to display opposing effects based on the subtype. Some of the clinical studies reference retrospective studies with small sample size, thus extrapolation of the results from these studies to the wider population should be performed with caution. Finally, the mechanism by which STC1 participates in various pathophysiological processes in breast cancer remains to be fully elucidated. Therefore, larger clinical and experimental studies are required to verify the role of STC1 in breast cancer, as well as the potential mechanisms underlying its effects.

\section{Acknowledgements}

Not applicable.

\section{Funding}

The present review was supported by Scientific Research Program of Wuhan Health and Family Planning (grant nos. WX17Q38 and WZ18Q05) and The Research Program of Wuhan No. 1 Hospital, Wuhan Integrated TCM \& Western Medicine Hospital (grant no. 2017Y01).

\section{Availability of data and materials}

Data sharing is not applicable to this article, as no datasets were generated or analyzed during the current study.

\section{Authors' contributions}

FC, ZZ and FP contributed to data analysis and writing of the manuscript. $\mathrm{ZZ}$ was involved in the conception of the study. FC and FP were involved in the literature search for this systematic review. All authors have read and approved the final manuscript.

\section{Ethics approval and consent to participate}

Not applicable.

\section{Patient consent for publication}

Not applicable.

\section{Competing interests}

The authors declare that they have no competing interests.

\section{References}

1. Torre LA, Bray F, Siegel RL, Ferlay J, Lortet-Tieulent J and Jemal A: Global cancer statistics, 2012. CA Cancer J Clin 65: 87-108, 2015

2. Sørlie T, Perou CM, Tibshirani R, Aas T, Geisler S, Johnsen H, Hastie T, Eisen MB, van de Rijn M, Jeffrey SS, et al: Gene expression patterns of breast carcinomas distinguish tumor subclasses with clinical implications. Proc Natl Acad Sci USA 98: 10869-10874, 2001.

3. Cancer Genome Atlas Network: Comprehensive molecular portraits of human breast tumours. Nature 490: 61-70, 2012.

4. De Abreu FB, Wells WA and Tsongalis GJ: The emerging role of the molecular diagnostics laboratory in breast cancer personalized medicine. Am J Pathol 183: 1075-1083, 2013.

5. Redig AJ and McAllister SS: Breast cancer as a systemic disease: A view of metastasis. J Intern Med 274: 113-126, 2013.

6. Yoshiko Y and Aubin JE: Stanniocalcin 1 as a pleiotropic factor in mammals. Peptides 25: 1663-1669, 2004

7. Chang AC, Janosi J, Hulsbeek M, de Jong D, Jeffrey KJ, Noble JR and Reddel RR: A novel human cDNA highly homologous to the fish hormone stanniocalcin. Mol Cell Endocrinol 112: 241-247, 1995.

8. Chang AC, Jeffrey KJ, Tokutake Y, Shimamoto A, Neumann AA, Dunham MA, Cha J, Sugawara M, Furuichi Y and Reddel RR: Human stanniocalcin (STC): Genomic structure, chromosomal localization, and the presence of CAG trinucleotide repeats. Genomics 47: 393-398, 1998.

9. Jellinek DA, Chang AC, Larsen MR, Wang X, Robinson PJ and Reddel RR: Stanniocalcin 1 and 2 are secreted as phosphoproteins from human fibrosarcoma cells. Biochem J 350: 453-461, 2000. 
10. Olsen HS, Cepeda MA, Zhang QQ, Rosen CA, Vozzolo BL and Wagner GF: Human stanniocalcin: A possible hormonal regulator of mineral metabolism. Proc Natl Acad Sci USA 93: 1792-1796, 1996.

11. Deol HK, Varghese R, Wagner GF and Dimattia GE: Dynamic regulation of mouse ovarian stanniocalcin expression during gestation and lactation. Endocrinology 141: 3412-3421, 2000.

12. Chang AC, Jellinek DA and Reddel RR: Mammalian stanniocalcins and cancer. Endocr Relat Cancer 10: 359-373, 2003.

13. Stasko SE and Wagner GF: Stanniocalcin gene expression during mouse urogenital development: A possible role in mesenchymal-epithelial signalling. Dev Dyn 220: 49-59, 2001.

14. Zhang KZ, Westberg JA, Paetau A, von Boguslawsky K, Lindsberg P, Erlander M, Guo H, Su J, Olsen HS and Andersson LC: High expression of stanniocalcin in differentiated brain neurons. Am J Pathol 153: 439-445, 1998.

15. He LF, Wang TT, Gao QY, Zhao GF, Huang YH, Yu LK and Hou YY: Stanniocalcin-1 promotes tumor angiogenesis through up-regulation of VEGF in gastric cancer cells. J Biomed Sci 18: $39,2011$.

16. Yeung BH, Law AY and Wong CK: Evolution and roles of stanniocalcin. Mol Cell Endocrinol 349: 272-280, 2012.

17. Liu G, Yang G, Chang B, Mercado-Uribe I, Huang M, Zheng J, Bast RC, Lin SH and Liu J: Stanniocalcin 1 and ovarian tumorigenesis. J Natl Cancer Inst 102: 812-827, 2010.

18. Du YZ, Gu XH, Li L and Gao F: The diagnostic value of circulating stanniocalcin-1 mRNA in non-small cell lung cancer. J Surg Oncol 104: 836-840, 2011.

19. Han J, Jeon M, Shin I and Kim S: Elevated STC-1 augments the invasiveness of triple-negative breast cancer cells through activation of the JNK/c-Jun signaling pathway. Oncol Rep 36: 1764-1771, 2016

20. Murai R, Tanaka M, Takahashi Y, Kuribayashi K, Kobayashi D and Watanabe N: Stanniocalcin-1 promotes metastasis in a human breast cancer cell line through activation of PI3K. Clin Exp Metastasis 31: 787-794, 2014.

21. Jeon M, Han J, Nam SJ, Lee JE and Kim S: STC-1 expression is upregulated through an $\mathrm{Akt} / \mathrm{NF}-\kappa \mathrm{B}$-dependent pathway in triple-negative breast cancer cells. Oncol Rep 36: 1717-1722, 2016.

22. Chang AC, Doherty J, Huschtscha LI, Redvers R, Restall C, Reddel RR and Anderson RL: STC1 expression is associated with tumor growth and metastasis in breast cancer. Clin Exp Metastasis 32: 15-27, 2015.

23. Zhang $Y$ and Zhai X: The correlation between the expression level of STC1 and the pathological parameters of breast cancer metastasis and chemotherapy resistance. J Clin Pathol Res 36: 1585-1588, 2016 (In Chinese).

24. McCudden CR, Majewski A, Chakrabarti S and Wagner GF: Co-localization of stanniocalcin-1 ligand and receptor in human breast carcinomas. Mol Cell Endocrinol 213: 167-172, 2004.

25. Zandberga E, Zayakin P, Ābols A, Pūpola D, Trapencieris P and Linē A: Depletion of carbonic anhydrase IX abrogates hypoxia-induced overexpression of stanniocalcin-1 in triple negative breast cancer cells. Cancer Biol Ther 18: 596-605, 2017.

26. Wascher RA, Huynh KT, Giuliano AE, Hansen NM, Singer FR, Elashoff D and Hoon DS: Stanniocalcin-1: A novel molecular blood and bone marrow marker for human breast cancer. Clin Cancer Res 9: 1427-1435, 2003.

27. Brantley KD, Kjærsgaard A, Cronin-Fenton D, Yacoub R, Nielsen AS, Lauridsen KL, Hamilton-Dutoit S and Lash TL: Stanniocalcin expression as a predictor of late breast cancer recurrence. Cancer Epidemiol Biomarkers Prev 27: 653-659, 2018.

28. Li JT, Li H and Hu GH: The expression of STC1 is related to lung metastasis in breast cancer. Fudan Univ J Med Sci 42: 618-622, 2015 (In Chinese).

29. Joensuu K, Heikkilä P and Andersson LC: Tumor dormancy: Elevated expression of stanniocalcins in late relapsing breast cancer. Cancer Lett 265: 76-83, 2008

30. Welcsh PL, Lee MK, Gonzalez-Hernandez RM, Black DJ, Mahadevappa M, Swisher EM, Warrington JA and King MC: BRCA1 transcriptionally regulates genes involved in breast tumorigenesis. Proc Natl Acad Sci USA 99: 7560-7565, 2002.

31. Chang AC and Reddel RR: Identification of a second stanniocalcin cDNA in mouse and human: Stanniocalcin 2. Mol Cell Endocrinol 141: 95-99, 1998.

32. DiMattia GE, Varghese R and Wagner GF: Molecular cloning and characterization of stanniocalcin-related protein. Mol Cell Endocrinol 146: 137-140, 1998 .
33. Ishibashi K, Miyamoto K, Taketani Y, Morita K, Takeda E, Sasaki S and Imai M: Molecular cloning of a second human stanniocalcin homologue (STC2). Biochem Biophys Res Commun 250: 252-258, 1998 .

34. White KE, Biber J, Murer H and Econs MJ: Chromosomal localization of two human genes involved in phosphate homeostasis: The type IIb sodium-phosphate cotransporter and stanniocalcin-2. Somat Cell Mol Genet 24: 357-362, 1998.

35. Moore EE, Kuestner RE, Conklin DC, Whitmore TE, Downey W, Buddle MM, Adams RL, Bell LA, Thompson DL, Wolf A, et al: Stanniocalcin 2: Characterization of the protein and its localization to human pancreatic alpha cells. Horm Metab Res 31: 406-414, 1999.

36. Charpentier AH, Bednarek AK, Daniel RL, Hawkins KA, Laflin KJ, Gaddis S, MacLeod MC and Aldaz CM: Effects of estrogen on global gene expression: Identification of novel targets of estrogen action. Cancer Res 60: 5977-5983, 2000.

37. Bouras T, Southey MC, Chang AC, Reddel RR, Willhite D, Glynne R, Henderson MA, Armes JE and Venter DJ: Stanniocalcin 2 is an estrogen-responsive gene coexpressed with the estrogen receptor in human breast cancer. Cancer Res 62: $1289-1295,2002$

38. Raulic S, Ramos-Valdes Y and Dimattia GE: Stanniocalcin 2 expression is regulated by hormone signalling and negatively affects breast cancer cell viability in vitro. J Endocrinol 197: 517-529, 2008

39. Iwao K, Matoba R, Ueno N, Ando A, Miyoshi Y, Matsubara K, Noguchi S and Kato K: Molecular classification of primary breast tumors possessing distinct prognostic properties. Hum Mol Genet 11: 199-206, 2002.

40. Yamamura J, Miyoshi Y, Tamaki Y, Taguchi T, Iwao K, Monden M, Kato K and Noguchi S: mRNA expression level of estrogen-inducible gene, alpha 1-antichymotrypsin, is a predictor of early tumor recurrence in patients with invasive breast cancers. Cancer Sci 95: 887-892, 2004.

41. Esseghir S, Kennedy A, Seedhar P, Nerurkar A, Poulsom R, Reis-Filho JS and Isacke CM: Identification of NTN4, TRA1, and STC2 as prognostic markers in breast cancer in a screen for signal sequence encoding proteins. Clin Cancer Res 13: 3164-3173, 2007

42. Coulson-Gilmer C, Humphries MP, Sundara Rajan S, Droop A, Jackson S, Condon A, Cserni G, Jordan LB, Jones LJ, Kanthan R, et al: Stanniocalcin 2 expression is associated with a favourable outcome in male breast cancer. J Pathol Clin Res 4: 241-249, 2018.

43. Takabatake Y, Oxvig C, Nagi C, Adelson K, Jaffer S, Schmidt H, Keely PJ, Eliceiri KW, Mandeli J and Germain D: Lactation opposes pappalysin-1-driven pregnancy-associated breast cancer. EMBO Mol Med 8: 388-406, 2016.

44. Argente J, Chowen JA, Pérez-Jurado LA, Frystyk J and Oxvig C: One level up: Abnormal proteolytic regulation of IGF activity plays a role in human pathophysiology. EMBO Mol Med 9: 1338-1345, 2017

45. Mansfield AS, Visscher DW, Hart SN, Wang C, Goetz MP, Oxvig C and Conover CA: Pregnancy-associated plasma protein-A expression in human breast cancer. Growth Horm IGF Res 24: 264-267, 2014

46. Ryan AJ, Napoletano S, Fitzpatrick PA, Currid CA, O'Sullivan NC and Harmey JH: Expression of a protease-resistant insulin-like growth factor-binding protein- 4 inhibits tumour growth in a murine model of breast cancer. Br J Cancer 101: 278-286, 2009.

47. Oxvig C: The role of PAPP-A in the IGF system: Location, location, location. J Cell Commun Signal 9: 177-187, 2015.

48. Millikan RC, Newman B, Tse CK, Moorman PG, Conway K, Dressler LG, Smith LV, Labbok MH, Geradts J, Bensen JT, et al: Epidemiology of basal-like breast cancer. Breast Cancer Res Treat 109: 123-139, 2008.

49. Curtis C, Shah SP, Chin SF, Turashvili G, Rueda OM, Dunning MJ, Speed D, Lynch AG, Samarajiwa S, Yuan Y, et al: The genomic and transcriptomic architecture of 2,000 breast tumours reveals novel subgroups. Nature 486: 364-352, 2012.

50. Lehmann BD, Bauer JA, Chen X, Sanders ME, Chakravarthy AB, Shyr Y and Pietenpol JA: Identification of human triple-negative breast cancer subtypes and preclinical models for selection of targeted therapies. J Clin Invest 121: 2750-2767, 2011.

51. Foulkes WD, Smith IE and Reis-Filho JS: Triple-negative breast cancer. N Engl J Med 363: 1938-1948, 2010.

52. Stevens KN, Vachon CM and Couch FJ: Genetic susceptibility to triple-negative breast cancer. Cancer Res 73: 2025-2030, 2013. 
53. Cleator S, Heller W and Coombes RC: Triple-negative breast cancer: Therapeutic options. Lancet Oncol 8: 235-244, 2007.

54. Huang S, Chi Y, Qin Y, Wang Z, Xiu B, Su Y, Guo R, Guo L, Sun H, Zeng C, et al: CAPG enhances breast cancer metastasis by competing with PRMT5 to modulate STC-1 transcription. Theranostics 8: 2549-2564, 2018.

55. Osborne CK: Steroid hormone receptors in breast cancer management. Breast Cancer Res Treat 51: 227-238, 1998.

56. Osborne CK, Yochmowitz MG, Knight WA III and McGuire WL: The value of estrogen and progesterone receptors in the treatment of breast cancer. Cancer 46 (Suppl 12): S2884-S2888, 1980

57. Amin MB, Edge S, Greene F, Byrd DR, Brookland RK, Washington MK, Gershenwald JE, Compton CC, Hess KR, Sullivan DC, et al (eds): AJCC Cancer Staging Manua[M]. 8th edition. New York, NY, Springer, 2017.

58. Hall JM, Lee MK, Newman B, Morrow JE, Anderson LA, Huey B and King MC: Linkage of early-onset familial breast cancer to chromosome 17q21. Science 250: 1684-1689, 1990.

59. Miki Y, Swensen J, Shattuck-Eidens D, Futreal PA, Harshman K, Tavtigian S, Liu Q, Cochran C, Bennett LM, Ding W, et al: A strong candidate for the breast and ovarian cancer susceptibility gene BRCA1. Science 266: 66-71, 1994.

60. Polyak K, Xia Y, Zweier JL, Kinzler KW and Vogelstein B: A model for p53-induced apoptosis. Nature 389: 300-305, 1997

61. Guo F, Li Y, Wang J, Li Y, Li Y and Li G: Stanniocalcin1 (STC1) inhibits cell proliferation and invasion of cervical cancer cells. PLoS One 8: e53989, 2013

62. Daniel AR and Lange CA: Protein kinases mediate ligand-independent derepression of sumoylated progesterone receptors in breast cancer cells. Proc Natl Acad Sci USA 106: 14287-14292, 2009.

63. Liu R, Wei S, Chen J and Xu S: Mesenchymal stem cells in lung cancer tumor microenvironment: Their biological properties, influence on tumor growth and therapeutic implications. Cancer Lett 353: 145-152, 2014.

64. Shirakawa M, Fujiwara Y, Sugita Y, Moon JH, Takiguchi S, Nakajima K, Miyata H, Yamasaki M, Mori M and Doki Y: Assessment of stanniocalcin-1 as a prognostic marker in human esophageal squamous cell carcinoma. Oncol Rep 27: 940-946, 2012.
65. Ito Y, Zemans R, Correll K, Yang IV, Ahmad A, Gao B and Mason RJ: Stanniocalcin-1 is induced by hypoxia inducible factor in rat alveolar epithelial cells. Biochem Biophys Res Commun 452: 1091-1097, 2014.

66. Durukan Tolvanen A, Westberg JA, Serlachius M, Chang AC, Reddel RR, Andersson LC and Tatlisumak T: Stanniocalcin 1 is important for poststroke functionality, but dispensable for ischemic tolerance. Neuroscience 229: 49-54, 2013.

67. Lal A, Peters H, St Croix B, Haroon ZA, Dewhirst MW, Strausberg RL, Kaanders JH, van der Kogel AJ and Riggins GJ: Transcriptional response to hypoxia in human tumors. J Natl Cancer Inst 93: 1337-1343, 2001.

68. Zhang KZ, Lindsberg PJ, Tatlisumak T, Kaste M, Olsen HS and Andersson LC: Stanniocalcin: A molecular guard of neurons during cerebral ischemia. Proc Natl Acad Sci USA 97: 3637-3642, 2000.

69. Law AY, Ching LY, Lai KP and Wong CK: Identification and characterization of the hypoxia-responsive element in human stanniocalcin-1 gene. Mol Cell Endocrinol 314: 118-127, 2010.

70. Maxwell PH, Dachs GU, Gleadle JM, Nicholls LG, Harris AL, Stratford IJ, Hankinson O, Pugh CW and Ratcliffe PJ: Hypoxia-inducible factor-1 modulates gene expression in solid tumors and influences both angiogenesis and tumor growth. Proc Natl Acad Sci USA 94: 8104-8109, 1997.

71. Zhong H, De Marzo AM, Laughner E, Lim M, Hilton DA Zagzag D, Buechler P, Isaacs WB, Semenza GL and Simons JW: Overexpression of hypoxia-inducible factor 1alpha in common human cancers and their metastases. Cancer Res 59: 5830-5835, 1999.

72. Harris AL: Hypoxia-a key regulatory factor in tumour growth. Nat Rev Cancer 2: 38-47, 2002.

This work is licensed under a Creative Commons Attribution-NonCommercial-NoDerivatives 4.0 International (CC BY-NC-ND 4.0) License. 